\title{
Indústria cultural gaúcha: dados sobre a oferta
}

\begin{abstract}
"Al investigar deseamos modificar ese ordenamiento para mejorar la representación, para mejorar la relación cognitiva del hombre con su medio y con ello permitir un comportamiento superior." (Jesús Galindo Cáceres)
\end{abstract}

\section{Histórico}

Esta pesquisa surge como projeto interinstitucional financiado pela Fundação de A mparo à Pesquisa do Estado do Rio Grande do Sul (FAPERGS), na linha de Grupos Emergentes, que visa apoiar a formação de grupos de pesquisadores envolvidos com pesquisas integradas. Foi desenvolvida durante 94 e 95.

Integra a produção docente do M estrado em Comunicação da Pontifícia Universidade Católica de Porto Alegre (PUC/ RS) desde o início e a partir de 95 a da Universidade Federal de Rio Grande do Sul (UFRGS), ano de fundação do M estrado em Comunicação desta Universidade. Ou seja, a história do projeto é anterior à criação dos referidos mestrados e, além disso, envolve outras instituições: a UniversidadeFederal deSanta Maria(UFSM)2 aU niversidadedeSantaCruz do Sul (UNISC) ea UniversidadeCatólica de Pelotas (UCPel), que foram convidadas a participar do projeto através de seus professores e/ ou alunos para realizar a pesquisa nas suas respectivas regiões.

Ao todo, cinco professores e 21 alunos participaram dapesquisa, al gunsdelesmesmo sem bolsa como os de Santa Cruz e Pelotas, além de muitos colaboradores, a maioria exalunos da UFSM que trabal ham em veículos e agências de publicidade nas cidades do interior. Foi formada uma rede que possibilitou otrabal hoereaproximou Universidade 
e mercado.

\section{$2 \quad$ Antecedentes}

Sua concepção está ligada imediatamente à falta de dados primários a respeito da estrutura da indústria cultural gaúcha, em seus vários aspectos, sentida em vários momentosdepesquisasanteriores realizadas pelos integrantes do grupo depesquisadores eem suas atividades didáticas na graduação, orientando monografias para os Projetos Experimentais.

Em termos mais gerais, está relacionado à vontadecomum deverificar certasafirmações correntesem determinadas vertentes do meio acadêmico e, na opinião corrente, sobre a capacidade dos meios de comunicação de desintegrar asculturaslocaiseregionais, sobre a padronização das ofertas culturais veiculadas especialmentepelo rádio ea televisão e sobre as particularidades dos jornais locais em cobrir fatos de caráter local, regional, nacional e internacional.

As perguntas motivadoras foram:

- qual éaestruturadosmeiosdecomunicação no Rio Grande do Sul?

- estas empresas estão ligadas a grupos nacionais e regionais ou pertencem a empresários locais?

- as empresaslocaispertencemaalgumarede ou são empreendimentos isolados?

- qual é a ligação com grupos políticos e religiosos?

- qual é a origem das empresas locais?

- qual é o perfil das emissoras AM eFM?

- qual é a programação destas emissoras?

- quanto desta programação contempla a produção cultural local e regional?

- quem decide sobre a programação e quais são os critérios?

- queemissoras deTV mantêm programação local/ regional?

- que gêneros de programas são produzidos localmente?

- e os jornais, como contemplam as informações locais, regionais, nacionais e internacionais?

- que seções fazem parte dos periódicos da capital e do interior gaúcho?

- a respeito da publicidade, qual éa inserção dosanunciantes locais, regionais, nacionaise internacionais nestesmeios decomunicação?

\section{Aporte teórico-metodológico}

A problemática desteestudo surgeapartir da consideração de que a cultura de massa, promovida pelos meios massivos, é um fenômeno intrínseco à cultura contemporânea. Daí a importância de estudar os meios de comunicação enquanto indústrias culturais. Conhecêlas "equivale a analisar detalhadamente o processo de produção/ comercialização em suas diferentes fases de criação/ concepção, edição, promoção, difusão e venda aos consumidores; pôr a descoberto as estruturas das unidades industriais (principalmente, formas e níveis deconcentração); enfim, colocar emevidência as estratégias dasempresas" (Matterlart, 1994, p. 230).

Emboratomando como ponto departida esta noção de indústrias culturais, não realizamos um trabalho de economia-política das indústrias culturais. Foi estratégico, neste primeiro momento, circunscrever a pesquisa à descrição das ofertas culturais, promovidas pelos meios de comunicação de massa 
gaúchos, analisando-as através de determinados referentes culturais. Por essa razão, nossa aproximação se dá através das relações entre comunicação e cultura.

A bandonamos o sentido de comunicacão estritamente relacionado ao de circulação de informações, assumindo a noção de comunicação enquanto práticas sociais. Estas podem ser entendidas enquanto práticas coletivas quando fal a-sedo sentido quea comunicação assume para os sujeitos. Mas, também, as práticas podem assumir o sentido deprodução cultural. Práticas culturais que expressam valores e significados promovidos por instituições, corporações, intel ectuais, a publicidade e a mídia em geral.

Dessa forma, estamos identificand o comunicação ecultura. N o entanto, épreciso reforçar nesta noção a dimensão de materialidade que o fenômeno cultural contém:

“A cultura (...) não é etérea, tem materialidade, pesa, tem volume e densidade. $\mathrm{Na}$ literatura sociológica, tem-se dado um lugar indiscutível ao estudo das formas de produção e das estruturas deorganização, cabeafirmar que existem poucos estudos que trabaIham a dimensão material da cultura. Muitas análises de discursos, muitas histórias das idéias edos criadores, mas poucos, muito poucos trabalhos que geraminformaçãoeinterpretaçõessobre as condições não somente discursivas do sentido, sobre a 'infraestrutura' material da cultura." (Gonzalez, 1995, p. 136)

Assumindo tais pressupostos, esta pesquisa tevecomo objetivo geral mapear a estruturae os conteúdos da indústria cultural sul-riograndense, considerando os jornais, as emissoras derádioAM eFM easemissoras de televisão.

Sobre a estrutura dos veículos estudados, registrou-sesua identificação nominal, razão social, cobertura geográfica e grupo empresarial. No caso dos meios impressos, acrescentou-se tiragem, circulação, formato, periodicidade e impressão. No estudo das emissoras de rádio, prefixo, freqüência, potênciaetempo deirradiação. Nasemissoras de televisão, prefixo, canal, tempo total de programação nacional, regional e local. Realizou-se, também, uma breve história de todos os veículos analisados, num total de 46 .

De uma forma geral, os conteúdos dos diversos mei os foram anal isados segundo os referentes local, regional, nacional einternacional. Para o local, foram rastreadas as informações sobreeparaacomunidadelocal. Paraoregional, asinformaçõessobreo Estado, de interesse circunscrito à comunidade gaúcha. Foram considerados conteúdos nacionais aqueles que extrapolam os limites doEstado, conservando-seno âmbito do país. $E$, internacionais, toda informação que não diz respeito ao território delimitado pelas fronteiras do país.

Essas relações, hoje, são complexas, dada a estruturaçãosocial contemporânea, imbricada na gl obalização da economia eda culturaque está dissolvendo as fronteiras até então estabelecidas. Por essa razão, foi bastante difícil implementar esses referentes.

Cada vez mais a sociedade vive um processo imposto pela lógica da massificação, o que não significa necessariamente homogeneização, pois os contextos histórico-culturais seguramente ainda (aliás, cada vez mais) pautam a produção cultural, mesmo a produção industrializadadaculturacomoéo caso da comunicação de massa.

Uma compreensão distinta deste fenômeno faz com que muitos autores afirmem que a indústria cultural enfraquece, quando não destrói, as culturas locais e regionais. Esta postura justifica-se a partir de um conceito rígido que entende a produção cultural massiva como algo uniforme, sem nuances locais e regionais, sem compromisso com os 
agentes sociais, quer sejam os produtores ou os consumidores. A esta posi ção, também, se associam outros atributos negativos ao massivo.

Hoje, é impossível negar a importância dos meios de comunicação de massa, que por serem deacesso mais fácil atodas as camadas populacionais, interligando hábitos, padrões de comportamento, ideologias, economias e culturas, distribuindo informações dos mais variados gêneros, participam efetivamente do cotidiano detodos, sem distinção. A opção éestudá-losem suacomplexidade. Conhecer sua estrutura e programação/ composição editorial (no caso dos meios impressos) éum dado fundamental para iniciar qualquer análise sobre a relação entre comunicação e cultura, qualquer queseja o objetivo: políticas culturais- estaduais emunicipais- processos derecepção, configuração dasaudiências, etc.

Pesquisas deste tipo, no Brasil, que possam servir dedadosprimáriosparaoutrosestudos, são raras. O que existe são dados coletados e divulgados por associações profissionais ou empresariais, como ABERT, gruposdemídia, AGERT, ADJORI, ANJ, que não raro são defasados e não cobrem veículos de menor penetração e muito menos dados sobre sua programação/ composição editorial.

Esta carência ou insuficiência dedados limita o conhecimento do potencial comunicacional do país e, especificamente, das regiões, além de dificultar estudos analíticos e interpretativos.

Estasituação seprolonga atéo Rio Grandedo Sul, motivando a real ização de um trabal ho empírico, que consideramos fundamental para detectar as configurações dos meios de comunicação noscontextoslocaiseregionais, as ofertas culturais propostas por estes agentes, as relações quese estabel ecem entre eles e suas audiências. N esta investigação, esteúltimo aspecto éapenasindicado através dedadosquantitativos, ou seja, pelosregistros de audiência dos veículos e programas.
Conhecer, então, o caso do Rio GrandedoSul, cuja densa rede comunicacional $^{3}$ o torna terceiro pólo da indústria cultural nacional, foi uma decisão importante que tem como objetivo fundamentar outros projetos de estudos mais amplos, por exemplo, elucidar as relações entreos meios decomunicação ea cultura local e regional. Isto é, ao privilegiar oestudo dosprincipaismeios decomunicação e seus produtos culturais em circulação no Estado, por entendê-los como agentes culturaisque, além deproduzir, reproduzem, reelaboram, ressignificam manifestações culturais, colocando-as em circulação, poderemos, numa segunda etapa, estudar sua inserção nas culturas locais e regional.

Devido a inexistência de condições de infraestrutura e pessoal, foi escolhida uma amostragem de cidades do Estado para realizar esta pesquisa. São elas: Porto A legre, Santa Maria, Santa Cruz do Sul, Pelotas, Rio Grande, Bagé, Uruguaiana, Santa Rosa, Erechim, Passo Fundo, Cruz Alta eCaxias do Sul. O motivo pelo qual estas foram as escolhidas foi a existência de uma infraestrutura de meios massivos, sendo fator decisivo na seleção a presença de uma emissora de televisão local, mesmo que funcionando em rede.

Com o objetivo de organizar a pesquisa, realizamos:

- numa primeira etapa, levantamento de dados em fontes já existentes (anuários de Mídia, AGERT, IBGE, IBOPE, ADJORI, ARI, entre outros); levantamento da grade da programação televisiva e radiofônica e da composição editorial dos meios impressos, assim como, coleta de dados sobre estrutura comercial, organização empresarial (vínculos com redes, concessões, propriedade individual, etc.) e histórico dos veículos em foco.

- numa segunta etapa, empreendemos um estudo piloto da indústria cultural - jornais diários, emissoras de rádios $A M$ e FM e emissoras detelevisão-dePorto Alegre, para 
testar as estratégias metodológicas;

- numa terceira etapa, estendemos a investigação àscidadesconsideradas pólosculturais do Estado.

Quanto às estratégias metodológicas, estas foram definidas e implementadas no estudo piloto em Porto A legre.

Assim, para o estudo da imprensa, foram selecionadososdoisprimeiroscolocadosentre os jornais diários de maior circulação na cidade. Entre os três existentes, dois foram analisados. ${ }^{4}$ Com o objetivo de estudar sua composição editorial, construímos uma amostragem com um total de 12 edições, selecionandoumexemplar por mês, seguindo a ordem dos dias da semana. A partir destas, foi descrita sua composição editorial, especificando editorias, seções, cadernos, colunas, etc. A quantificação das categorias Texto (títulos, chamadas, legendas, corpo da matéria), Fotografia, Ilustração (mapas, gráficos, etc.) eCharge, segundo os referentes local, regional, nacional e internacional, foi realizadamedianteo instrumental da análise morfológica, utilizando-se como unidade de medidadoespaço impresso o $\mathrm{cm}^{2}$. Por último, foi cal culado o espaço publicitário.

Em relação às emissoras radiofônicas, foram selecionadas duas emissoras de maior audiência dentro de cada categoria da classificação proposta pelo IBOPE - adulto, jovem, jornalística e popular. Deum total de 15 emissoras AM, foram estudadas 3. Deum total de 16 emissoras FM, foramanalisadas 5 . Alémdisso, foi estudadoo programademaior audiência de cada uma destas emissoras.

O estudo daprogramaçãofoi realizadoatravés degravação e deescuta deum dia deemissão de cada emissora, seguido de sua descrição, complementadacomasinformações coletadas junto às próprias emissoras. A informação mais relevante desta etapa foi a identificação dos gêneros ofertados por cada emissora, levantando sua proporcionalidade no total de programas que compõem cada programação. Foi medido, também, o tempo diário que cada gênero ocupa na programação das emissoras.

O programa de maior audiência de cada emissora foi analisado segundo os referentes já citados. Para tal, foram gravados três edições de cada um (segunda, quarta esexta) na última semana de dezembro de 1994 e primeira semana de janeiro de 1995. Estes foramanalisadossegundoo model o proposto por M oragas Spa ${ }^{6}$ quesofreu al gumas modificações.

Seguindo o modelo, o tempo foi medido em sua totalidade, composta pelas diferentes categorias e subgrupos da programação: músicacomounidadeautônoma(tempototal daemissão musical), publicidade(tempototal da emissão publicitária) e o restante do material sonoro (tempo total redacional juntamente com música auxiliar). Assim, foram destacados nos discursos falado, musical, publicitário tanto seus aspectos quantitativos quantosuas referênciasaolocal, regional, nacional e internacional.

No caso das emissoras de tel evisão, das seis existentes na cidade de Porto A legre foram anal isadas as quatro emissoras que apresentaram um índice de audiência superior a $1 \%$, segundo o IBOPE/ julho de 19957. A análise ficou restrita às produções regionais elocais, tendo sido selecionado o programa de mai or audiência de cada emissora para proceder a análise de conteúdo.

O modelo de análise dos programas seguiu em linhas gerais a proposta de Jorge A. González ${ }^{8}$. Registrou-seonomedo programa, dia da emissão, periodicidade, canal/ Rede, horário, origem da produção (regional/ local), gênero (informativo; educativo/ cultural; entretenimento), tipo (ficção ou não-ficção) e estrutura (blocos, espaços comerciais, apresentador, ...). A pós esta descrição, os programas foram analisados segundo os referentes culturais.Além disso, coletou-se 
informações sobre o espaço publicitário do horário da emissão destes programas.

Como as emissoras de televisão operam basicamenteem rede, esta estabel eceo tempo eo horário dos espaços regionais elocais. Isto significou que, nesta investigação, o estudo das emissoras de Porto Alegre mostrou a tendência da programação, pois esta é basicamente produzida nesta cidade e veiculada em nível estadual. A exceção fica com a RBS que mantém emissoras locais em 11cidadesdoInterior, destasforamestudadas as de Santa Maria e de Santa Cruz.

Nas cidades consideradas pólos culturais, a investigação seguiu as mesmas orientações metodológicas. No caso da pesquisa sobre imprensa, a composição da amostragem sofreu variações devido, principalmente, à periodicidade dos jornais. Entretanto, o principal jornal de cada cidade foi analisado sob os mesmos critérios já citados.

Quanto às emissoras de rádio, no Interior, pesquisamos a emissora AM e FM de maior audiência. Não foi considerada a tipologia proposta pelo IBOPE, pois na maioria delas não existe pesquisas de audiência. De cada umadasemissorasanalisadas, foi escolhidoo programa de maior audiência para análise.

Enfim, paraimplementação destasestratégias o projeto depesquisa foi subdividido em subprojetos com respectivas coordenações: Estudo daimprensano RS(PUC/ RS); Estudo das emissoras de rádio e televisão no RS e Estudo Piloto (UFRGS); Estudo dos meios de Santa Maria (UFSM); Estudo dos meios de Santa Cruz (UNISC). ${ }^{9}$

4 Algumas conclusões e hipóteses a explorar

Em primeirolugar, énecessário alertar parao fato de que não existe uma única leitura dos dados coletados. Isto significa que dependendodofoco privilegiado podemosal cançar explicações e interpretações distintas.

Por essa razão, privilegiamosnestemomento a perspectiva já comentada, na medida em que interessa verificar como essa indústria cultural - no caso, os jornais, emissoras de rádio e de televisão do RS - atua em relação aos interesses de âmbito local, regional, nacional einternacional.

A começar pelo estudo piloto, enfocando os jornais Zero HoraeCorreio do Povo, pode-se afirmar queo primeiroéumjornal, emtermos de conteúdo informativo, nacional e o segundo, regional. A Zero Hora destaca em segundo lugar o referente regional, sendo queo internacional fica muito próximo deste. Já o Correio do Povo privilegia em segundo lugar o referente nacional, sem ter uma diferença substancial com o âmbito regional . A pesar deprivilegiar os enfoques nacionaise regionais, a publicidadeem ambos concentra sua área comercial no âmbito local .

A respeito dasemissoras derádio, foi possível tecer uma análise mais detal hada, uma vez que são mais segmentadas e diferenciadas entre si. Assim pode-se tratar das emissoras primeiramente a partir da classificação do IBOPE comojornalísticas, populares, jovense adultas; pode-se enfocar as AMs e as FMs entresi, e todas em seu conjunto.

É importante destacar que, em termos dos gêneros, asemissorasjornalísticasprivilegiam oinformativona ofertadiáriadaprogramação; as emissoras populares e jovens concentram sua oferta nos gêneros musical e entretenimento; e entre as adultas, uma dedica-se total mente aogênero musical ea outradivideseentremusical eentretenimento. Emtermos do perfil das emissoras traçado a partir das grades de programações, utilizado pelo IBOPE e pelo mercado publicitário, os dados seconfirmam. Obviedadesqueserelativizam com uma análise mais detalhada:

- Entre as informativas, a Gaúcha oferece o gênero esportivo de forma significativa 
(35,2\%) ea Guaíbadedica parteda programação para o gênero musical (22\%), partepara o esportivo (16,7\%).

- Entre as populares, considerando as diferenças entre AMs e FMs, a Farroupilha AM oferece programas de serviço público presentes em $25 \%$ da programação, além de 12,5\% deinformativos; jáEldoradoFM dividese entre os gêneros musical e de entretenimento.

- Entreasjovens, AtlântidaFM eCidadeFM, a diferença repousa apenas na proporção invertida dos gêneros musical e entretenimento.

- As adultas (ambas FM) se diferenciam porque a Bandeirantes oferece programas informativos (24\%), esportivos (5\%) e de entretenimento (33\%), enquanto que a Continental é totalmente musical.

Se o foco for nas emissoras AMs em seu conjunto, os dados são díspares porqueentre elas há duas de perfil jornalístico e uma popular, enquanto queem termos das FM so padrão musical/ entretenimento semantém, mesmo com a Bandeirantes oferecendo informativos e esportivos.

Se o olhar recai sobre todas as emissoras estudadas, épossível dizer queo predomínio da programação oferecida em Porto A legreé de caráter musical e de entretenimento, definido pelasemissoras FM squeestão entre as mais ouvidas.

Passando para a análise dos programas de maior audiência, entre as jornalísticas, o discurso falado contempla o referencial nacional; o discurso musical não aparece na Gaúcha ena Guaíba contempla o nacional eo internacional. O discurso publicitário privilegia o referencial regional em ambas.

Entre as populares, encontram-se muitas semelhanças no discurso falado, que em ambas se remete ao local e em ambas o referentenacional aparececom umpercentual mínimo (1\%). A diferença se estabelece na contemplação do regional apenas pela Farroupilha, embora mínima (2\%). N as duas o discurso musical apresenta onacional como maior presença, e a ausência total dos referentes local e internacional. A diferença aparece na presença do regional apenas na Farroupilha. O discurso publicitário remetese semel hantemente ao contexto local.

N as emissoras jovens, os discursos falado e publicitário são de referência local em maior percentual, sendo que o falado o é quase totalmente. A diferença se dá no discurso musical, que dispensa os referentes locais e regionais, poisambas dedicam-setotalmente ao nacional e ao internacional, sendo que a Atlântida majoritariamente para o internacional ea Cidade para o nacional.

Asemissorasadultasapresentamumagrande diferença no que diz respeito ao discurso falado, pois a Continental apenas anuncia o nome das músicas a serem rodadas, já a Bandeirantes remete-se ao contexto nacional e internacional prioritariamente. Quanto ao discurso musical, ambas excluem o local e regional, sendo que a Bandeirantes dedica metade para o nacional, metade para o internacional e a Continental privilegia o internacional.

Quanto à televisão, devido às características geradas pela formação de redes, o objetivo primordial da pesquisa-piloto foi conhecer os conteúdosemitidosna programação produzida em Porto A legre, tanto de cobertura local quanto regional, uma vez que a gerência/ geração de programação se encontra nesta cidade.

A ssim, pode-sedizer quehácertassemel hanças entreas ofertas por gênero entrea RBSTV (filiada à Globo) e a Bandeirantes: priorizam o informativo, seguido do esportivo, e cultural. O SBT não produz nenhum programa local ea Pampa (Rede M anchete) oferece apenas os gêneros informativo e entretenimento. Mas se a análise considerar 
o tempo dedicado a cada gênero, observase que a Bandeirantes, que não é uma rede gaúcha, dedicamaistempo ao esporte local/ regional do quea RBS, etem quaseo mesmo tempo deproduçãolocal do gênero informativo, só superada pela RBS no gênero cultural com o dobro do tempo dedicado a ele.

Em termos de tempo ainda, a dedicação ao gênero informativo inclui praticamente no mesmo patamar a Pampa, que supera todas as outras emissoras (8h e $45 \mathrm{~min}$. semanais), também dedicando muitas horas ao gênero entretenimento (11h e $30 \mathrm{~min}$ ), só ofertado pelaRBS, entreas demais, mas com menos da metade do tempo (4h e 54 min) em relação à Pampa.

No que diz respeito aos referentes culturais, podemos dizer que o programa de maior audiência daBandeirantesenfatizao discurso faladolocal eo discurso publicitário regional; o da RBS enfatiza os discursos falado e publicitário regional; o daTV Pampa prioriza o discurso falado local e a publicidade regional. O SBT não tem programa de produçãolocal, entretanto, veiculacomerciais de anunciantes locais.

Para o Interior como um todo, guardando as diferenças apresentadas pelas pesquisas, Santa Maria e Santa Cruz que incluem todos osmeiosdecomunicação existentesnacidade ePelotas que só excluiu a televisão, fica mais difícil tecer considerações generalizadas porque os dados apontam para algumas diferenças, explicáveis pelo tamanho e estrutura do mercado publicitário, estrutura ecaracterísticasdarededecomunicaçãolocal, nível deprofissionalismo easpectosculturais de cada cidade e região.

A homogeneidadeem relação aos conteúdos de caráter local, analisados nos jornais e emissoras de rádio, foi identificada em Bagé, Uruguaiana (fronteiriças respectivamente com Uruguai e Argentina), Cruz Alta, Santa Cruz do Sul, Santa Maria e Pel otas.
Caxias do Sul, Erechim, Passo Fundo, Santa Rosa não apresentaram uma tendência homogênea, sendo a programação musical das FM so fator definidor, pois apontam para os referenciais nacional e internacional. 0 que significa por outro lado que os jornais confirmaram-secomo meios eminentemente locais.

Em cidades como Santa Maria, Santa Cruz, Caxias do Sul e Passo Fundo, tidas como pólos regionais, aparecem percentuais significativos com referência ao regional, especialmente nos jornais e nos discursos publicitários..

É preciso levar em conta nestes resultados a presença em muitas destas cidades da emissoraA tlântidaFM, pertencenteao grupo RBS, queem geral está em primeiro lugar nos índices de audiência, o que significa que outras emissoras locais ficaram fora da amostra, o que poderia indicar outras tendências em termos deprogramação local/ regional.

Relendo o relatório, sob outras perspectivas, já há sinalização de algumas hipóteses para trabalhos futuros:

- as FMs jovens são transclassistas e se inserem da mesma forma em diversas regiões e locais?

- como se relaciona a cultura étnica de uma cidadedecolonizaçãoalemãcomoSantaCruz, com os meios de comunicação, haja vista que a presença ao vivo de bandas alemãs é marcante nas emissoras locais?

- qual é o perfil da programação de gênero musical dedicado ao regionalismo e qual éa relação com o público?

- qual é a importância, no Interior, dos programas dos gêneros educativo, religioso, deutilidadepública, queaparecem com mais freqüência na grade de programação do que nas rádios da capital? 
- diante da estratégia mercadológica de tom regionalista e da constatação de que o jornal de maior circulação no Estado dedica maior espaço aos assuntos decaráter nacional, qual é a demanda e identificação dos leitores?

- e os canais de televisão pertencentes às redes nacionais como constroem sua relação com a audiência e o com o mercado?

Também, no sentido da continuidade deste estudo, jáforam implementadosa montagem de um banco de dados aberto para alunos e pesquisadores; a criação de um núcleo de pesquisas sobreestudos demídianaUFRGS, para desenvolver estudos sobre os dados levantados e a vinculação de pesquisas e projetos de monografias e dissertações de mestrado.

\section{Limites e problemas enfrentados}

O maior problema foi de ordem operacional, pois a inexistência de dados mínimos, como por exemploohistórico dasempresas, desviou grandepartedo tempo edo foco da pesquisa, rendendo por outro lado o fato de que a pesquisa escreveu a história e o perfil dos veículos estudados. Este foi um dos fatores responsáveis por não haver resposta para algumas perguntasformuladas inicialmente, um dos limites da pesquisa.

Isto e a não informatização da pesquisa dificultou a análise e reduziu o poder explicativo dosdados, deixando-ano patamar da descrição, o que não diminui a sua importância, mas nos deixou aquém da expectativa inicial.

\section{Notas}

1 Texto apresentado no "II Seminário sobre as Tendências da Pesquisa deComunicação nos Cursos de Pós- Graduação"I XIX Congresso Brasileiro de Ciências da Comunicação. Londrina, setembro de 1996.0 presentetext foi baseado na pesquisa "A indústria Cultural Gaúcha: estudo dos meios de comunicação de massa e sua inserção na cultura local e regional". Financiada pela FAPERGS e realizada por Ana Carolina Escosteguy, Dóris Haussen, Marli Hatje, Nilda Jacks (coordenação geral) e Veneza Ronsini.

2 Através do Programa Especial de Treinamento (PET).

3 Segundo dados do Mídia-Brasil by M CCann 1992/93, 8\% dos canais de televisão estão no Rio Grande do Sul (isto significa 24 canais), assim como, 12\% das rádios AM (75 emissoras), 12\% das rádios FM (135 emissoras) e 9\% dos títulos de jornal (174). Além disso, 82\% dos domićílios gaúchos possuem TV e 93,3\% possuem rádio, maior posse de rádio no País.

4 Segundo dados do IBOPE, de julho de 1994, os jornais que ocupavam esta posiç̧ão eram: Zero HoraeCorreio do Povo.

5 As emissoras estudadas foram: Gaúcha AM, Guaíba AM, Farroupilha AM, Cidade FM, Atlântida FM, Bandeirantes FM, Continetal FM eEIdorado FM. Osprogramas analisados foram respectivamente: "Gaúcha Hoje", "Flávio Alcaraz Gomes Repórter", "Comando Maior", "faixa horária das 14 às 17h," "faixa horária das 14 às 17h", "Rota 99 primeira edição", "Musical Rotativo I" e "Peça e Ofereça”.

6 MORAGAS SPA, M. (1976) "Perspectiva semiótica de la comunicación radiofônica(análisisde21 horasdeemisión)". In: MORAGAS SPA, M. Semiótica y comunicación de masas. Barcelona, Ed. Península.

7 As emissoras são: RBS TV, SBT, Bandeirantes e Pampa (Manchete).

8 VerGONZALEZ,Jorge (1988) “Lacofradíadelasemociones (in)terminables". In: Revista Estudios sobre las culturas contemporâneas, n. 4-5, Colima/ México, Universidad de Colima.

9 As respectivas coordenações ficaram a cargo das seguintes pesquisadoras: AnaCarolinaD. Escosteguy (PUCRS), Nilda Jacks(UFRGS), VenezaMayoraRonsini (UFSM), Marli Hatje (UNISC).

\section{Referências}

MATTELART, Armand. (1994) Comunicação-mundo. Petropólis, Vozes. 
GONZALEZ, JorgeA. (1995) "Coordenadas del imaginários" In revista Estudios sobre las culturas contemporâneas, Época II Vol. I N.2 Colima, México, Universidad de Colima.

GONZALEZ, Jorge A. (1988) "La cofradía de las emociones (in)terminables". Revista Estudios sobre las culturas contemporâneas, n 4-5, Colima, México, Universidad de Colima.

CANCLINI, Néstor García. (1983) As culturas populares do capitalismo. São Paulo, Brasiliense.

MARTíN-BARBERO, Jesús (1987) De los medios a las mediaciones. Barcelona, Gustavo Gilli.

MATTA, Maria Cristina e SCARAFIA, Silvia. (1993) Lo que dicen las radios. Quito, Aler.

SPA, Miguel Moragas de. (1976) "Perspectiva semiótica de la comunicación radiofônica". Semiótica y comunicación de masas. Barcelona, Ed. Península.

WILLIAMS. Raymond. (1978) Los medios de comunicación social. Barcelona, Ed. Península.

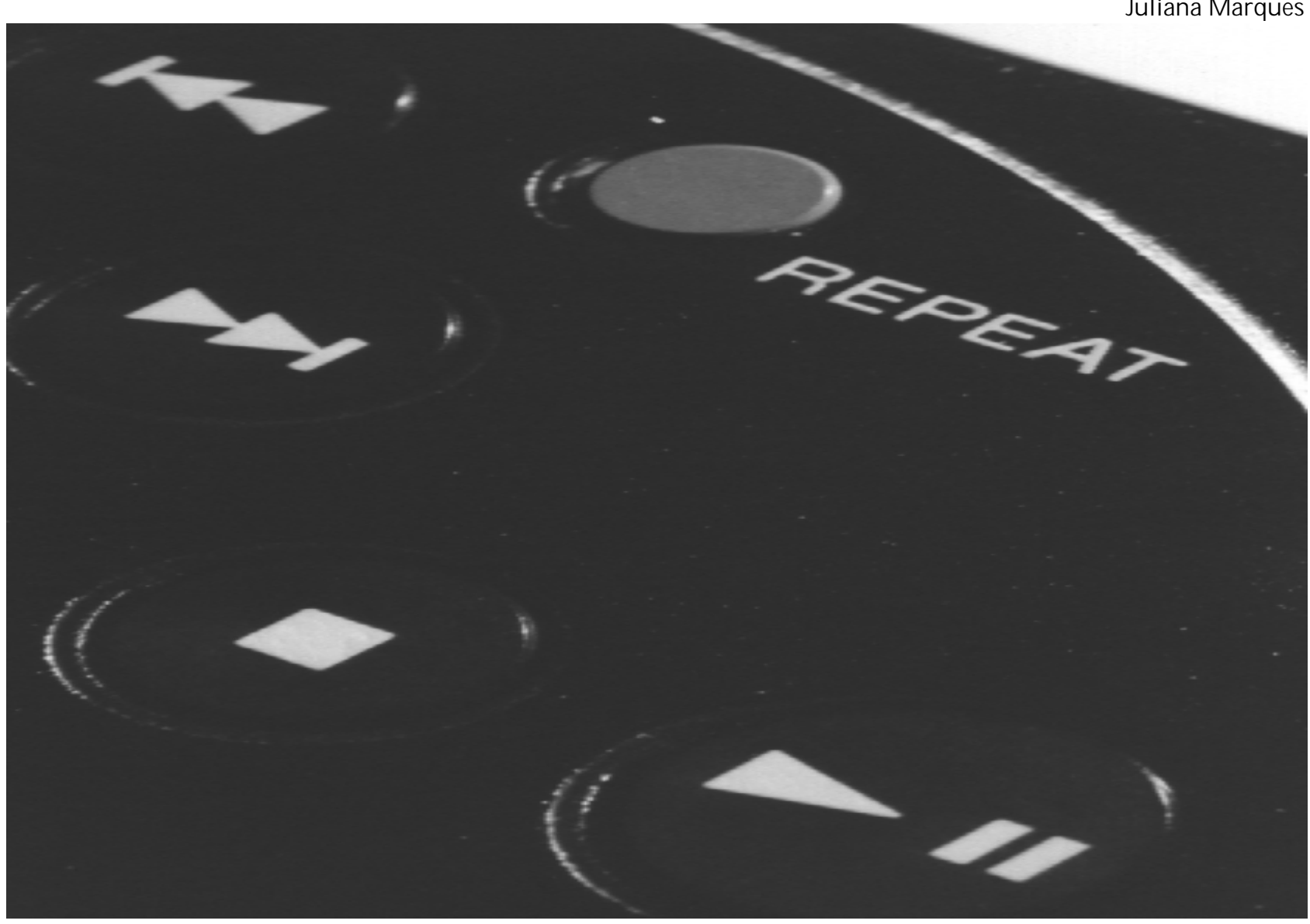

